Global Business Research Congress, June 10-11, 2021

\title{
THE FUTURE OF SALES: SOCIAL SELLING
}

\author{
DOI: 10.17261/Pressacademia.2021.1413 \\ PAP- V.13-2021(2)-p.6-11
}

\section{Anil Serifsoy}

Isik University, Institute of Social Sciences, Istanbul, Turkey. anilserifsoy@gmail.com, ORCID: 0000-0002-7930-8045

\author{
To cite this document \\ Serifson, A. (2021). The future of sales: social selling. PressAcademia Procedia (PAP), V.13, 6-11 \\ Permanent link to this document: $h$ ttp://doi.org/10.17261/Pressacademia.2021.1413 \\ Copyright: Published by PressAcademia and limited licensed re-use rights only.
}

\begin{abstract}
Purpose- This paper aims to be an exploratory study, to shed light on subsequent researches regarding the changing sales craft in a changing world.

Methodology-- Internet-based research is conducted to amass the essential information on the changing sales techniques in the new world. Findings- As a result of the research, significant differences are observed in the art of sales, along with the inclusion of the Generation- $Z$ in business, with social media which has become a part of our life and with the changing world under the darkness of COVID 19.

Conclusion- This article is aimed to be an initial step for a guide intended for salespeople and business owners to take appropriate action and adapt their sales strategies to the new world.
\end{abstract}

Keywords: Social selling, social media, digital environment, adaptation, brand new selling technique JEL codes: M10, M12, M19

\section{INTRODUCTION}

"It is not the strongest of the species that survives, nor the most intelligent that survives. It is the one that is the most adaptable to change." As it is explained by Charles Darwin, change is the only thing that doesn't change in the world. And within this changing world, adaptability is the key to success or indeed, even survivability. Business is the reflection of wildlife. Just as various living beings that have gone extinct throughout the history; millions of examples could be found in business world, who could not have adapted and lost their chances to continue their journey in business life.

Sales are the backbone of the business and it is not surprising to see the techniques used for sales have been changing throughout history. Buying behavior of the customer has been changing depending on millions of variables such as production ways, wars, innovations, and so on. Especially within recent years, the increasing pace of digitalization and pandemics have changed the entire habits of the customers. Even though they do not have the opportunity to go outside and spend hours shopping, people are shopping more frequently. In another words, even though we are all stuck in our houses, we became more social. Moreover, we are able to socialize and connect with millions of people when we are buying something.

The intention of the article is to be an exploratory study that showcases the considerable changes in salescraft in order to fulfill the changing demands of the new generation of customers.

\section{LITERATURE REVIEW}

Change is the only thing that never changes and it plays an enormous role in life. The way we are living, the way we are learning and for sure the way we are earning have been changing over time under the great effect of the developing technology. According to the articles that describe the stages of business and commerce, barter was the only way for the interactions of people and to create the opportunity to continue their life in a better way by exchanging the products they have with each other. It was first recorded in Egypt, started by farmers that were eager to exchange the farm animals with harvest or dairy products and food that were produced with their experience and their expertise. Many historians think that this stage was the major force that evolves the communication skill of human beings. Due to the limited production and resources, they wanted to attain goods or services beyond what they had. Later, with the development of the division of labor and the increase in the variety of commercial goods, a common means of exchange became needed. Bread, pearl, gold, and silver became more popular for daily trade (BOZKURT).i 
First of all, business took another step with the discovery of writing around $3500 \mathrm{BC}$. After that, as it is described by the sources from Herodotus, "the Lydians were the first people to use gold and silver coins and the first to establish retail shops in permanent locations" (Herodotus), (Britannica, 2016). It was followed by the creation of trade routes; which is seen as the first step of becoming a global village. The second step for globalization was the acceptance of Florin by the entire Europe. As it is mentioned by Dave Barry "In prehistoric times, there was no such thing as money. Some people need to buy something they had to charge it. And then when the bills came, nobody could understand them because there was also no such thing as reading. this leads to a lot of misunderstanding and hitting with rocks." (Choron \& Choron, 2011). This was a new era not only for entire Europe but also for the entire world to show how trade can be changed with the cooperation of the nations.

As the trade is modified over time, the backbone of the business has also changed day by day. Especially after the second world war, the entire business was acting on a different platform. The mentality was generally on capturing the attention of the customer. The interaction of buyer and seller increased after that era under the effect of marketing 2.0 and marketing 3.0. The bond between seller and buyer which was seen as the single channel was getting stronger day by day to keep the satisfaction in the top level for the customer. However, with the change of technology, this single-channel mentality has been transformed to e-commerce, multichannel, cross-channel, and finally omnichannel to respond to every single request of the customer in no time and keep them aware of every single point.

For sure, technology made it possible to reach the customer through as many channels as possible and had a better result reaching out to the customer, making it easier to get them aware of the brand and the product. After the popularity of e-commerce, multichannel and crosschannel became more possible to apply and interact with the customer.

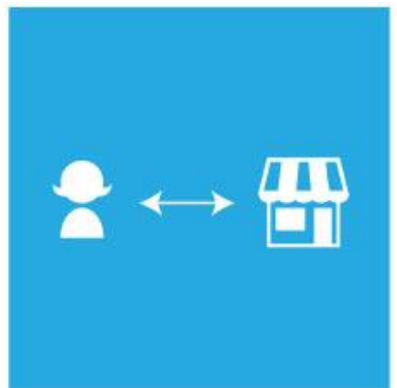

Single Channel

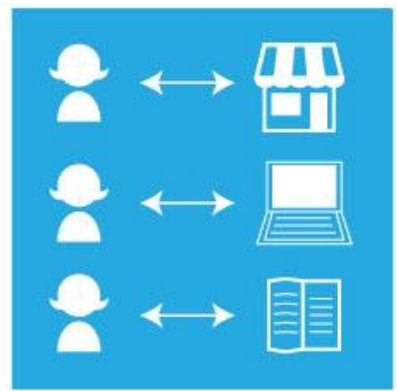

Multi Channel

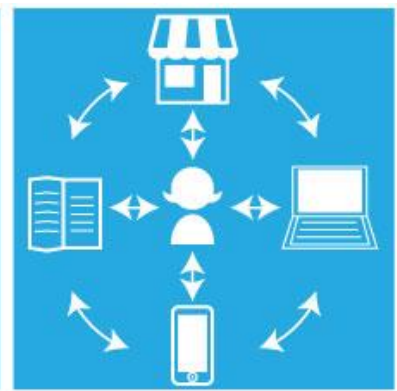

Omnichannel

(Nichols \& Schneider, 2015)

As omnichannel is defined "Omnichannel is the idea of using all of your channels to create one, unified experience for your customers. This includes both traditional and digital channels, point-of-sale, in-store, and online experiences" (Omnisend, 2021). With the great advantage comparing to multichannel marketing "Omnichannel marketing is an approach that provides customers (Rahul Sharma, 2020) with a completely seamless and integrated shopping experience from the first touchpoint to the last. That means that each channel works together to create a unified message, voice, and brand for your company" With the latest approach, "Unlike multichannel marketing, omnichannel marketing keeps the message relevant by having each channel update as the customer engages with your brand. Multichannel marketing has largely static messages across several channels, but those channels don't update and personalize with your customers' needs." (Rahul Sharma, 2020). The greatest advantage of omnichannel marketing comparing to multichannel is while multichannel marketing puts the brand and the product in the center of the main goal, omnichannel marketing puts the customer at the center of the strategy. That makes omnichannel a better way to communicate with the customer and make them a part of the integration instead of seeing them as only a way of earning money and pressure them to buy the goods.

As it is mentioned in the description of the omnichannel, internet is playing a bigger role than traditional marketing channels. Emails, websites and chats become a part of omnichannel marketing. However, the main feedback of the customer is generally collected by social media. That puts social media on the top of the list of channels. Especially with the involvement of the younger generations and with the popularity of social media among all age groups, it has become one of the indispensable parts of the business to involve every single person to guarantee the future of the brand. 


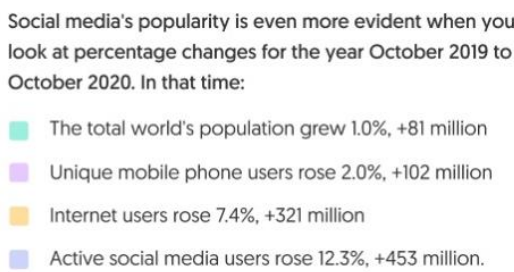

The total world's population grew $1.0 \%,+81$ million

Unique mobile phone users rose $2.0 \%,+102$ million

Internet users rose $7.4 \%,+321$ million

Active social media users rose $12.3 \%,+453$ million.

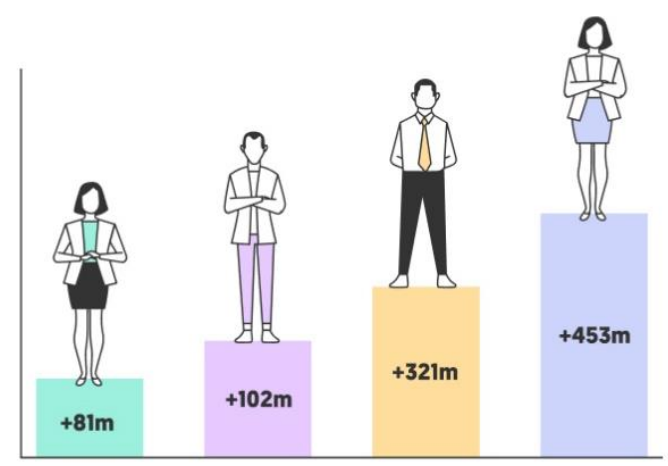

(Influencer Marketing Hub, 2020)

As mentioned by the sources, the population of active social media users is getting growing more than the increase of the population of the world. Especially with the involvement of the new generation, the average age of the active users is getting lower day by day and social media is becoming an immense part of daily life. But what is the reason for the increase of active social media users being even higher than the rise of internet users? According to the report of the Hootsuite, there are tens of different reasons to be on social media including staying up to date with news and events, following entertaining content, fill up spare time, stay in touch with friends, sharing photos or videos, networking with the people, meet new people and so on (Hootsite, 2021).

As Covid 19 has changed everything in our lives, it has also played a big role in society and the usage of social media. The vast majority of the population had to stay at home in order to not get infected. The use of digital platforms has become indispensable for people to socialize in the absence of face-to-face interaction.

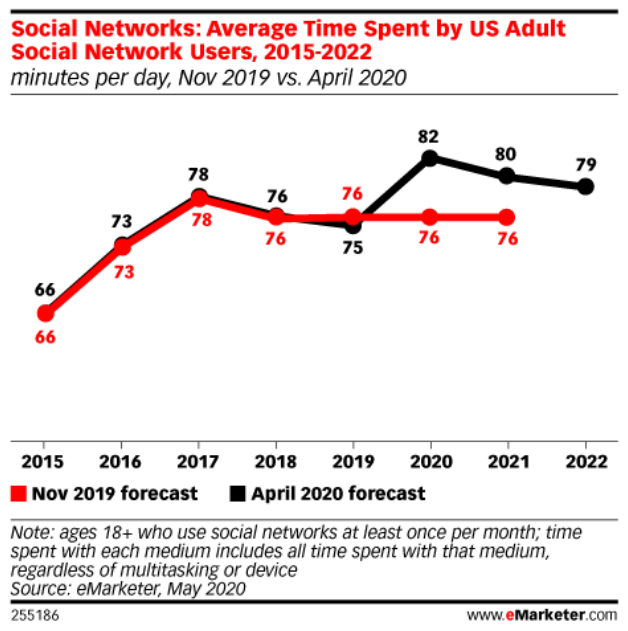

(Freer, 2020)

Companies that had difficulty in maintaining their presence in the market with traditional methods had to be more innovative and had to turn the current process in their favor. This naturally led to the transfer of marketing expenditures from the traditional to the innovative side. This is perfectly visible with the social media spending throughout the pandemic 
The CMO Survey":"

February 2021

\section{Social media spending is up 4.3 points in the last 5 years, but} expected to rise almost 10 points in the next 5 years

What percent of your marketing budget are you currently spending on social media? And what percent will you spend in the next 12 months? 5 years?
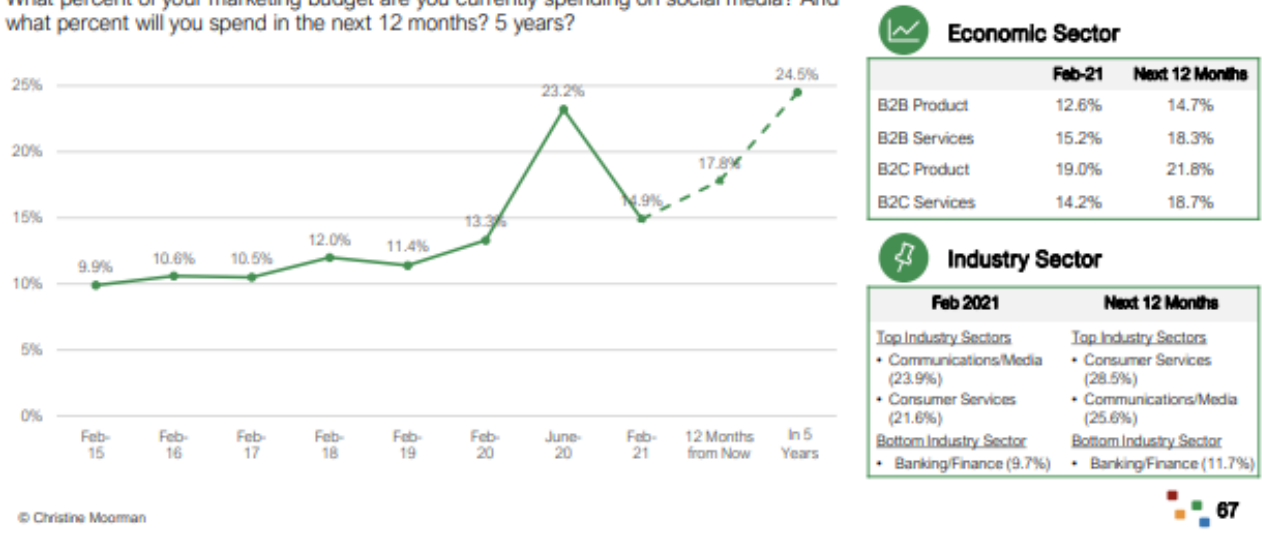

(Moorman, 2021)

All the companies understand the importance of digitalization and the usage of social media, especially within this period. Companies have many different reasons for using social media. According to The CMO Survey; brand awareness, retain customers, acquire new customers, and brand promotions are the main reasons for the companies to follow this new trend. (Moorman, The CMO Survey, 2020)

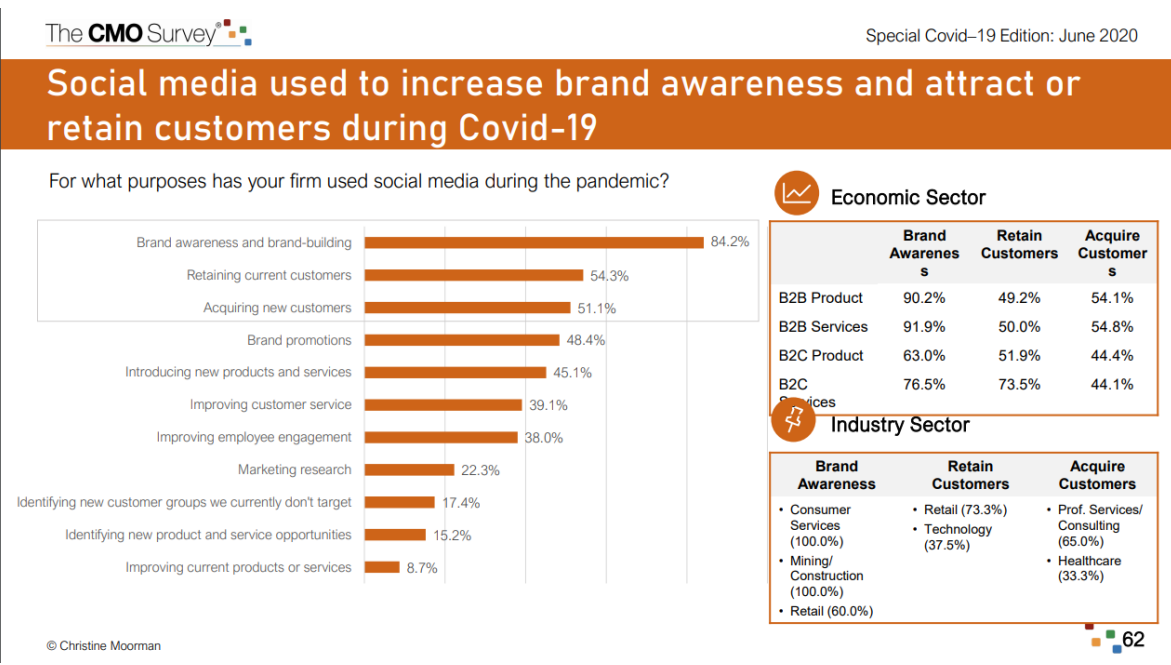

(Moorman, The CMO Survey, 2020)

Companies that use social media actively wanted to establish a more integrated system into the existing one as a result of the benefits they realized. As it is described in many articles, social selling is a new technique that combines selling and marketing efforts which are based on the social media platforms such as LinkedIn, Twitter, Instagram, and others. "Social media has had an enormous impact on buying behavior with $49 \%$ of sellers seeing social media as important to their success. In fact, among the most successful salespeople, over two-thirds believe social media is integral to their sales success" (Fetherstonhaugh, 2021).

As described in articles, the benefit of social selling is extensive, and following this trend is necessary with the changing world.

1. New Buyer Journey: Today's customer is more conscious and has great knowledge of what they are buying with the help of the internet and they can easily skip some steps without the involvement of the sellers.

2. Triggering Effect: Inform the customer and trigger them by attracting their attention and force them to act as soon as possible

3. Referral Selling: Uses the satisfaction of the existing customer for the potential sales. 
4. Insight Selling: With to the point content which shows the benefit of the product, the way that helps to fulfill the requirement of the customer and the number of the user and benefitted from it provides important information to the potential buyers that affect their decision in the decision stage.

5. New listening skills: With the digital traces, most of the companies collect valuable information about the customer including their interests and what they are searching for in recent days.

6. Co-Creation and collaboration: The involvement of the customer in every single stage of the production with the feedback taken from them.

(Fetherstonhaugh, 2021) (Dealsinsight, 2020) (Moore, 2019)

Although "social selling" is an innovative way of selling, it has clear differences from traditional selling. "They perceive it like any other selling strategy and thus prioritize the selling first. On the contrary, social selling is first about social and then about selling. Since social channels are connected to real people, take some time to engage in authentic conversations, build real connections, and then gradually suggest your solution to their long-drawn problems" (Dealsinsight, 2020).

\section{DATA AND METHODOLOGY}

Secondary data is the way to attain valuable information for this study. Initial knowledge is earned with the review of the latest literature on the topic. The main reason for writing this article is not only describe the mentality of the change on sales but also notify the companies according to the changes and warn them to adapt to the new era to increase the chance of their survivability in the future. Sales are the main building blocks of the business. Therefore it is dynamic and it has an intention to change from the way it was a year ago. For such a dynamic structure; the most recent literature, which in itself is rare in this specific topic, should be reviewed and It should be gathered up as a guide to enlighten the researchers about the new sales techniques. Internet-based research is fundamental for this article. This article will provide a good starting point and intended to become the initial state for further studies by handling the background information related to the new sales techniques.

Archival research starting with the external data to obtain the essence of the concepts and continuing with the data taken from the reports of the global consulting firms provide the backbone for this article. The deficiency of articles related to this subject leads explorers to focus on written by the global consultancy companies. Their findings reflect the situation with financial statements and real numbers that come from comprehensive surveys.

\section{CONCLUSION}

Resilience, adaptation, sustainability, and digitalization are among the most popular terms in recent years. Especially with the challenges of Covid-19, these terms gained more importance for all companies. In order to achieve success in the aforementioned terms, choosing the right channels plays a vital role. Social media, which reached its wide usage rate in a time period not too long ago is one of the best ways for companies, because especially after Covid-19 it became crucial for the companies to be available and reachable to the target customer for wherever the customers expect to engage, interact and transact with the supplier. That is why social media is one of the right channels to exist because that makes the companies available to the target customer wherever and whenever they need it. And most importantly it is not all about selling, it is all about leveraging and nurturing relationship with the customer through the digital and social world and create a long-lasting relationship which leads to long term business relationship.

\section{REFERENCES}

Bozkurt, P. D. (n.d.). Istanbul Ticaret Üniversitesi Dergisi. Retrieved from TICARETIN FELSEFESI, TARIHÇESI VE ETIKLE OLAN SIKI BAĞINA ILIŞKIN BAZi SAPTAMALAR: http://acikerisim.ticaret.edu.tr/xmlui/bitstream/handle/11467/194/M00030.pdf?sequence=1\&isAllowed=y

Britannica. (2016). 1911 Encyclopædia Britannica/Herodotus. Retrieved from

https://en.wikisource.org/wiki/1911_Encyclop\%C3\%A6dia_Britannica/Herodotus

Choron, S., \& Choron, H. (2011). Money: Everything You Never Knew About Your Favorite Thing to Find, Save, Spend, and Covert. Chronicle Books.

Dealsinsight. (2020). Digital Selling and Social Selling. Retrieved from The future of B2B Sales: https://www.dealsinsight.com/digital-sellingand-social-selling-the-future-of-b2b-sales/

Fetherstonhaugh, B. (2021). Sales Talent Agency. Retrieved from The Future of Selling: It's Social: https://www.salestalentagency.com/blog/the-future-of-selling-its-social/

Freer, A. (2020, July 6). Business of Apps. Retrieved from Post-pandemic social media usage unsustainable: https://www.businessofapps.com/news/post-pandemic-social-media-usage-unsustainable/

Herodotus. (n.d.). History. Retrieved from 94:

http://www.perseus.tufts.edu/hopper/text?doc=Perseus:text:1999.01.0126:book=1:chapter=94

Hootsiite. (2021). Digital in 2020. Retrieved from Reasons for using social media: https://wearesocial.com/digital-2020

Influencer Marketing Hub. (2020). Social Media Usage. Retrieved from More Than 4 Billion People Worldwide Now Use Social Media: https://influencermarketinghub.com/social-media-benchmark-report-2021/ 
Moore, G. (2019). Vengreso. Retrieved from Why The Future of Selling Requires a Different Kind of Seller: https://vengreso.com/blog/gregmoore-future-of-selling

Moorman, C. (2020). The CMO Survey. Retrieved from Social Media: https://cmosurvey.org/wpcontent/uploads/2020/06/The_CMO_Survey-Highlights-and_Insights_Report-June-2020.pdf

Moorman, C. (2021). The CMO Survey. Retrieved from The Transformation of Marketing: Emerging Digital, Social and Political: https://cmosurvey.org/wp-content/uploads/2021/02/The_CMO_Survey-Highlights_and_Insights_Report-February-2021.pdf

Nichols, K. P., \& Schneider, R. A. (2015). Omnichannel Content Strategy. Retrieved from Definitions: https://omnichannelcontentstrategy.com/definitions/

Omnisend. (2021). What is Omnichannel Marketing? (+4 Best Practices for Ecommerce). Retrieved from https://www.omnisend.com/blog/omnichannel-marketing/

Quote Investigator. (2014, May). Charles Darwin. Retrieved from https://quoteinvestigator.com/2014/05/04/adapt/

Rahul Sharma. (2020). Linkedin. Retrieved from What is Omni Channel: https://www.linkedin.com/pulse/what-omni-channel-rahul-sharma/ 